\title{
Self-Assembled Hybrid Nanoparticles for Cancer-Specific Multimodal Imaging
}

\author{
Jason S. $\operatorname{Kim}^{\dagger}$, William J. Rieter ${ }^{\dagger}$, Kathryn M. L. Taylor ${ }^{\dagger}$, Hongyu An ${ }^{\ddagger}$, Weili Lin ${ }^{\ddagger}$, and Wenbin \\ Lin ${ }^{\dagger}$ \\ $\dagger$ Department of Chemistry, University of North Carolina, Chapel Hill, NC 27599 \\ $\$$ Department of Radiology, University of North Carolina, Chapel Hill, NC 27599
}

Multifunctional nanoparticles (MFNPs) have shown great promise as new probes for biomedical imaging and carriers for drug delivery. ${ }^{1}$ MFNPs can not only carry large payloads of imaging and/or therapeutic agents, but also be rendered target-specific by conjugation to affinity molecules which have avidity for cell surface markers. Although a number of strategies have been developed to synthesize target-specific MFNPs, most of them rely on covalent attachment of affinity molecules to their surfaces. ${ }^{2}$ Since such bioconjugation steps can be tedious, there exists a need for new synthetic strategies toward imaging and/or therapeutic MFNPs that can specifically target diseased cells. Herein we wish to report a noncovalent, electrostatic layer-by-layer (LbL) self-assembly strategy for the synthesis of cancer-specific MFNPs that are efficient contrast agents for multimodal imaging.

LbL self-assembly, which was first reported almost 25 years ago, ${ }^{3}$ utilizes a wide range of interactions of varied strength, including covalent bonds, ${ }^{4}$ metal-ligand coordination, ${ }^{5}$ and electrostatic attractions between oppositely charged polyelectrolytes. ${ }^{6}$ Whereas molecular self-assembly was initially developed for depositing monolayer and multilayer films on planar substrates, electrostatic LbL self-assembly of polyelectrolytes has recently been shown to be a versatile strategy for the synthesis of core-shell nanostructures and nanoshells. ${ }^{7}$ In this work, we have prepared cancer-specific MFNPs by LbL self-assembly of polyelectrolytes and explored their in vitro applications in magnetic resonance (MR) and optical imaging.

Scheme 1 illustrates our LbL self-assembly strategy for MFNPs which were synthesized starting from recently reported hybrid silica nanoparticles (NP0) containing a luminescent $[\mathrm{Ru}$ (bpy) 3$] \mathrm{Cl}_{2}$ core and a paramagnetic monolayer coating of the Gd-(siloxylpropyl)

diethylenetriamine tetraacetate (Gd-DTTA) complex. ${ }^{8}$ NP0 is a highly anionic nanoparticle owing to the negative charge on the Gd-DTTA complex and, as a result, allows the deposition of cationic Gd(III)-DOTA oligomer 1 via electrostatic interactions to afford NP1A. It has been shown that nanoparticles terminated with positively charged polyelectrolytes carry net positive charge to allow further deposition of anionic polymers via electrostatic interactions. ${ }^{7}$

Treatment of NP1A with polystyrenesulfonate (PSS) yielded NP1B with a bilayer of 1 and PSS. Repetition of this LbL deposition sequence led to MFNPs with alternate multilayer coatings of positively charged $\mathbf{1}$ and negatively charged PSS. These MFNPs are designated NPnA or NPnB with $\mathbf{n}$ denoting the number of $\mathbf{1}$ or PSS coating and $\mathbf{A}$ and $\mathbf{B}$ denoting surface termination with $\mathbf{1}$ and PSS, respectively.

TEM images indicated alternate deposition of $\mathbf{1}$ and PSS onto the nanoparticles (Figure 1a-c); the average diameters for NP1A, NP3A, and NP6A are $37 \pm 1,41 \pm 1$, and $43 \pm 2 \mathrm{~nm}$, respectively.

E-mail: wlin@unc.edu. 
As shown in Figure 1d, the average diameters of the nanoparticles linearly increased as more bilayers of $\mathbf{1}$ and PSS were deposited. To further probe alternate deposition of $\mathbf{1}$ and PSS, we have prepared a fluorescein isothiocyanate (FITC)-labeled cationic Gd-DOTA oligomer 1a. Upon excitation at $488 \mathrm{~nm},\left[\mathrm{Ru}(\mathrm{bpy})_{3}\right] \mathrm{Cl}_{2}$-doped $\mathbf{N P 0}$ emitted at $615 \mathrm{~nm}$ whereas the FITC dye emitted at $515 \mathrm{~nm}$. Since the luminescence intensity at $615 \mathrm{~nm}$ is proportional to the NP0 concentration, the ratio of the $515 \mathrm{~nm}$ emission intensity to $615 \mathrm{~nm}$ emission intensity is proportional to the number of FITC molecules on each nanoparticle. As shown in Figure 1e, the ratio between $515 \mathrm{~nm}$ emission and $615 \mathrm{~nm}$ emission increased quadratically as more layers of 1a and PSS were deposited. This result is consistent with the linear increase of particle diameter since the number of FITC molecules is proportional to the surface area of spherical nanoparticles (which scales quadratically with the particle diameter).

We have determined longitudinal ( $\mathrm{r} 1$ ) and transverse ( $\mathrm{r} 2)$ MR relaxivities for the LbL nanoparticles (NPnA) with up to seven layers of $\mathbf{1}$. Interestingly, the relaxivity values for NPnA on a per Gd basis remain essentially constant at $\mathrm{r} 1=19.0 \pm 1.7 \mathrm{mM}^{-1} \cdot \mathrm{s}^{-1}$ and $\mathrm{r} 2=55.0 \pm 5.0$ $\mathrm{mM}^{-1} \cdot \mathrm{s}^{-1}$ regardless the number of deposited layers of $\mathbf{1}$. This result is in stark contrast with that of the nanoparticles with covalently-attached multilayers of $\mathrm{Gd}$ chelates which exhibited diminished relaxivities on a per Gd basis. ${ }^{8}$ We believe that the highly disordered and hydrophilic nature of $\mathbf{1}$ and PSS on NPnA allows ready accessibility of water molecules to the $\mathrm{Gd}$ centers for efficient water proton relaxation. Based on the size of LbL particles, we further estimated r1 and $\mathrm{r} 2$ relaxivities for NPnA on a per particle basis which increased linearly as more layers of 1 were electrostatically deposited onto NPO (Figure 2a). The per particle r1 values increase from $1.94 \times 10^{5} \mathrm{mM}^{-1} \cdot \mathrm{s}^{-1}$ for NP0 to $5.34 \times 10^{5} \mathrm{mM}^{-1} \cdot \mathrm{s}^{-1}$ for NP7A whereas the per particle $\mathrm{r} 2$ values increase from $5.61 \times 10^{5} \mathrm{mM}^{-1} \cdot \mathrm{s}^{-1}$ for $\mathbf{N P 0}$ to $1.55 \times 10^{6} \mathrm{mM}^{-1} \cdot \mathrm{s}^{-1}$ for NP7A. The LbL self-assembly thus offers a superb strategy for increasing nanoparticle MR relaxivities.

Since LbL self-assembled nanoparticles (NPnB) are terminated with anionic PSS polymers, we hypothesized that NPnB can be further non-covalently functionalized with targeting peptides that carry positive charges under physiological conditions. A peptide sequence containing arginine-glycine-aspartate (RGD) and seven consecutive lysine (K) residues $\left(\mathrm{K}_{7} \mathrm{RGD}\right)$ was chosen for this study. The negatively charged PSS layer can electrostatically interact with positively charged lysine residues of the $\mathrm{K}_{7} \mathrm{RGD}$ sequence to lead to surface functionalization of NPnB particles with the RGD sequence. The RGD peptide is known to bind strongly (with a $\mathrm{K}_{\mathrm{d}}$ in the $\mu \mathrm{M}$ range) to the integrin cell surface receptors that are upregulated in growing endothelial and angiogenic cancer cells. ${ }^{9}$ We used human colon cancer (HT-29) cells and calf pulmonary artery endothelial (CPAE) cells for in vitro labeling studies. HT-29 cells are known to overexpress integrin receptors 10 and have been previously labeled with $\mathrm{K}_{7} \mathrm{RGD}$-functionalized protein microspheres. ${ }^{11}$

T1-weighted MR images of HT-29 cells after incubation with various nanoparticles are shown in Figure 2b. Significant signal enhancement in the T1-weighted image was observed only for HT-29 cells incubated with NP3B particles that have been non-covalently functionalized with the $\mathrm{K}_{7}$ RGD sequence. In contrast, no signal enhancement was observed for the HT-29 cells incubated with either NP5B particles or NP5B particles non-covalently functionalized with the $\mathrm{K}_{7} \mathrm{GRD}$ sequence. The $\mathrm{K}_{7} \mathrm{GRD}$ peptide was used here as a scramble to mimic the surface charge of the nanoparticles but without providing affinity for the integrin receptors. In vitro MR imaging studies demonstrated efficient targeting of cancer cells by the LbL particles with non-covalently attached $\mathrm{K}_{7}$ RGD peptide.

We have confirmed the targeting capability of LbL nanoparticles using laser scanning confocal fluorescence microscopic (LSCFM) imaging. As shown in Figures 2c-2j, significant luminescent signal was observed for HT-29 cells incubated with NPnB particles that have been 
non-covalently functionalized with the $\mathrm{K}_{7} \mathrm{RGD}$ sequence, indicating efficient targeting of HT-29 cells by the electrostatically attached $\mathrm{K}_{7}$ RGD peptide. In comparison, no or little luminescent signal was observed for control HT-29 cells without nanoparticles and for the cells that had been incubated with NP5B particles or NP5B particles non-covalently functionalized with the scrambled $\mathrm{K}_{7} \mathrm{GRD}$ sequence. This result has been further supported by LSCFM studies of CPAE cells which also showed cell targeting by the NPnB particles with non-covalently attached $\mathrm{K}_{7} \mathrm{RGD}$ peptide (supporting info).

In summary, we have utilized electrostatic LbL self-assembly to construct MFNPs with both MR and optical imaging capabilities. The LbL self-assembly strategy not only affords MFNPs with extraordinarily high MR relaxivities but also provides an efficient means for non-covalent functionalization of MFNPs with affinity molecules. The generality of this approach should allow the design of imaging and/or therapeutic MFNPs that can specifically target a wide range of diseased cells.

\section{Supplementary Material}

Refer to Web version on PubMed Central for supplementary material.

\section{ACKNOWLEDGMENT}

We acknowledge financial support from NIH (U54-CA119343 and P20 RR020764). We thank Dr. Aiguo Hu for providing 1 and 1a and Dr. Rihe Liu for access to his tissue culture facility. WJR thanks NSF for a graduate fellowship and WL is a Camille Dreyfus Teacher-Scholar.

\section{References}

1(a). Bertin PA, Gibbs JM, Shen CK-F, Thaxton CS, Russin A, Mirkin CA, Nguyen ST. J. Am. Chem. Soc 2006;128:4168. [PubMed: 16568958] (b) McCarthy JR, Kelly KA, Sun EY, Weissleder R. Nanomedicine 2007;2:153. [PubMed: 17716118] (c) Torchilin VP. Adv. Drug Delivery Rev 2006;58:1532. (d) Rhyner MN, Smith AM, Gao X, Mao H, Yang L, Nie S. Nanomedicine 2006;1:209. [PubMed: 17716110] (e) Morawski AM, Lanza GA, Wickline SA. Curr Opin. Biotechnol 2005;16:89. [PubMed: 15722020] (f) Giri S, Trewyn BG, Stellmaker MP, Lin VS. Angew. Chem. Int. Ed 2005;44:5038. (g) Hu M, Chen J, Li ZY, Au L, Hartland GV, Li X, Marquez M, Xia Y. Chem. Soc. Rev 2006:1084. [PubMed: 17057837]

2. Hermanson, GT. Bioconjugate Techniques. Academic Press; San Diego: 1996.

3. Nuzzo RG, Allara DL. J. Am. Chem. Soc 1983;105:4481.

4(a). Love JC, Estroff LA, Kriebel JK, Nuzzo RG, Whitesides GM. Chem. Rev 2005;105:1103. [PubMed: 15826011] (b) Lin W, Lin W, Wong GK, Marks TJ. J. Am. Chem. Soc 1996;118:8034.

5. Fang M, Kaschak DM, Sutorik AC, Mallouk TE. J. Am. Chem. Soc 1997;119:12184.

6. Decher G. Science 1997;277:1232.

7(a). Schneider G, Decher G. Nano Lett 2004;4:1833. (b) Schneider G, Decher G. Nano Lett 2006;6:530. [PubMed: 16522057] (c) Caruso F, Caruso RA, Möhwald H. Science 1998;282:1111. [PubMed: 9804547] (d) Shchukin DG, Sukhorukov GB, Möhwald H. Angew. Chem. Int. Ed 2003;42:4472.

8. Rieter WJ, Kim JS, Taylor KML, An H, Lin W, Tarrant T, Lin W. Angew. Chem. Int. Ed 2007;46:3680.

9(a). Folkman J. Nature Med 1995;1:27. [PubMed: 7584949] (b) Folkman J. N. Engl. J. Med 1995;333:1757. [PubMed: 7491141]

10. Lee JW, Juliano RL. Mol. Biol. Cell 2000;11:1973. [PubMed: 10848623]

11. Toublan FJ-J, Boppart S, Suslick KS. J. Am. Chem. Soc 2006;128:3472. [PubMed: 16536492] 

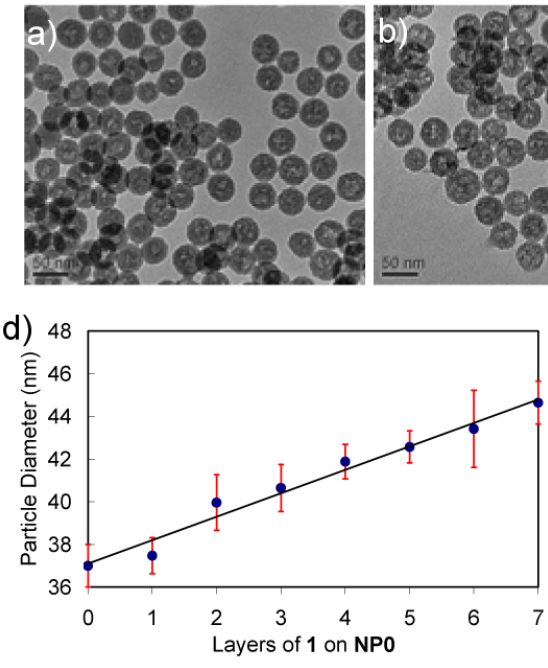
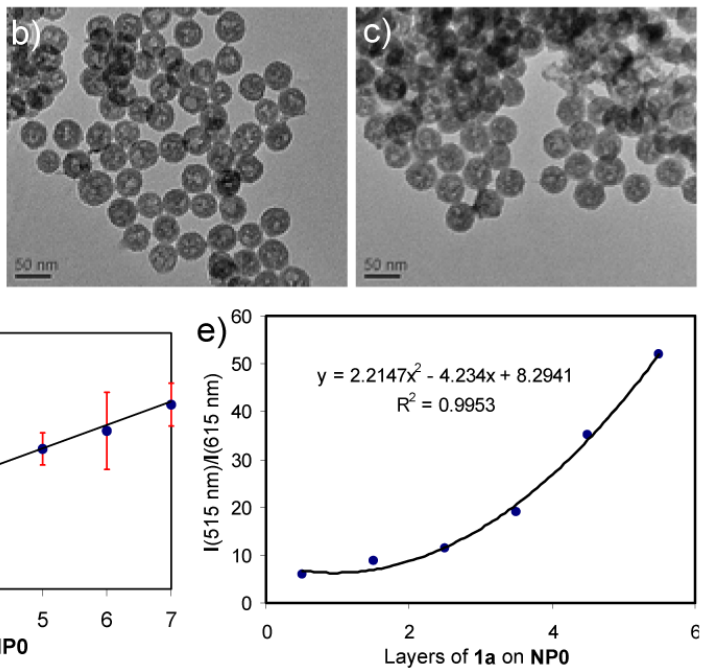

Figure 1.

(a-c) TEM images of nanoparticles that have been terminated with cationic Gd-DOTA oligomer 1: (a) NP1A; (b) NP3A; (c) NP6A. (d) Dependence of NPnA particle size on the number of deposited 1. (e) Dependence of the intensity ratio between FITC (515 nm) and [Ru $\left.(\text { bpy })_{3}\right]_{C l}(615 \mathrm{~nm})$ luminescence on the number of deposited FITC-labeled Gd-DOTA oligomer 1a. 

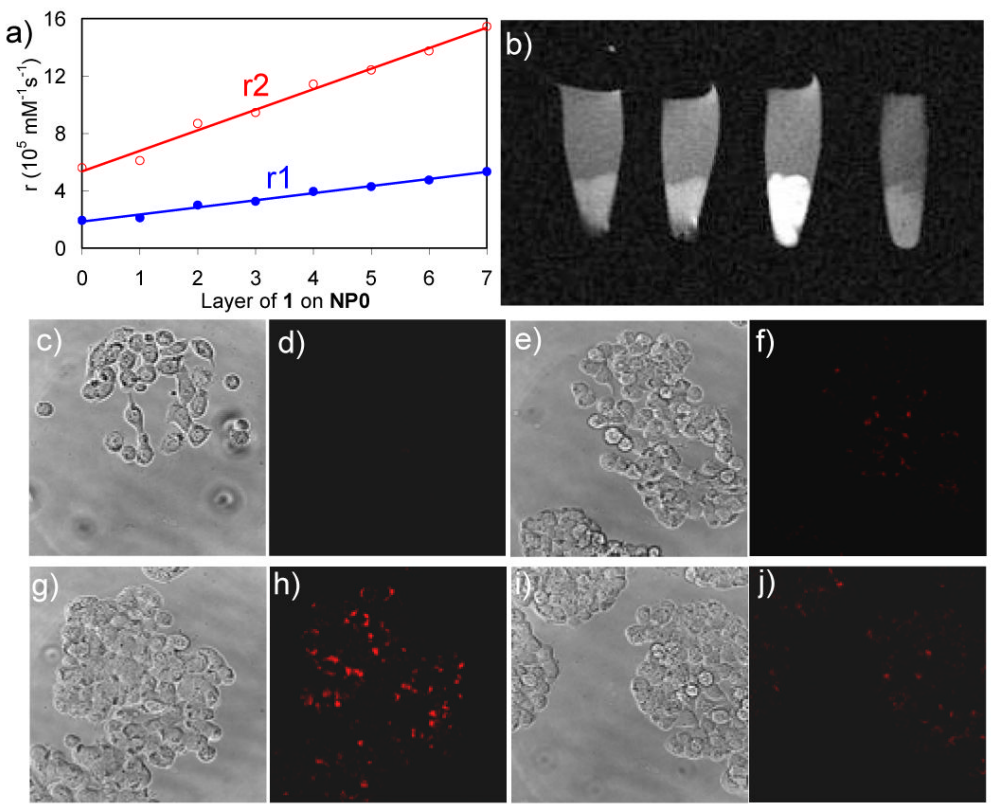

Figure 2.

(a) Dependence of per particle $\mathrm{r} 1$ and $\mathrm{r} 2$ values on the number of deposited Gd-DOTA oligomer 1 on NP0. (b) T1-weighted MR images of HT-29 cells that have been incubated with various nanoparticles. From left to right: control cells without any nanoparticle, cells with NP3B

particles, cells with NP3B particles that have been non-covalently functionalized with $\mathrm{K}_{7} \mathrm{RGD}$, and cells with NP3B particles that have been non-covalently functionalized with $\mathrm{K}_{7} \mathrm{GRD}$. (cj) Phase contrast optical (c, e, g, and i) and LSCFM microscopic images (d, f, h, and j) of HT-29 cells that have been incubated with various nanoparticles: control cells without any nanoparticle (c and d), cells with NP5B particles (e and f), cells with NP5B particles that have been non-covalently functionalized with $\mathrm{K}_{7} \mathrm{RGD}$ ( $\mathrm{g}$ and $\mathrm{h}$ ), and cells with NP5B particles that have been non-covalently functionalized with $\mathrm{K}_{7} \mathrm{GRD}$ ( $\mathrm{i}$ and $\mathrm{j}$ ). 


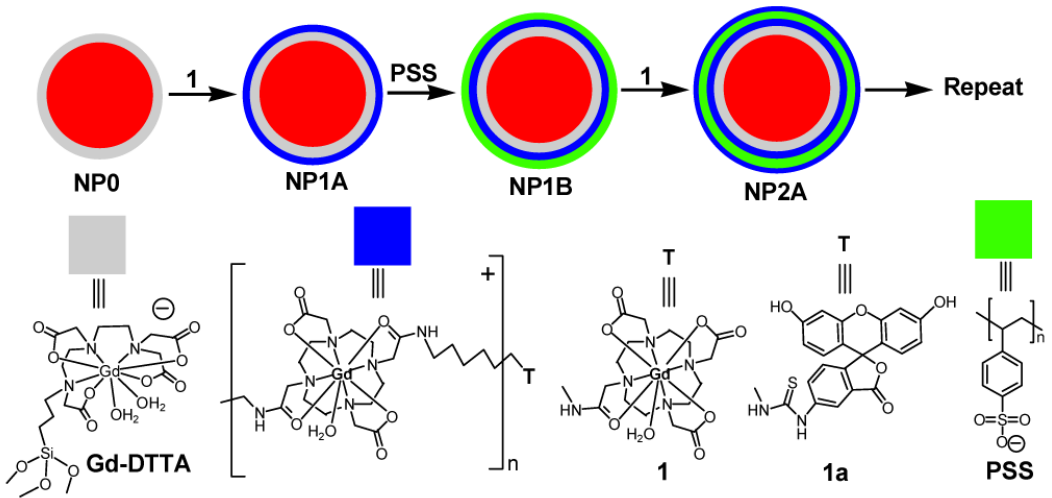

Scheme 1. 